\title{
El hombre como animal cultural en el tratamiento de Carlos París
}

\author{
LORENZO PEÑA \\ Instituto de Filosofia del CSIC
}

Es Cárlos París uno de los filósofos españoles que se han ido preocupando más - a lo largo de muchas obras sobradamente conocidas del público filosófico- en analizar, desde diversas perspectivas, al scr humano, su peculiaridad, sus facetas, siempre en tanto en cuanto ello comporta problemas genuinamente filosóficos y necesita un tratamiento que trasciende al de los saberes particulares y de los especialistas; mas tambićn siempre en diálogo con cuanto tengan que aportar esos mismos especialistas, sin ruptura ninguna entre el quehacer filosófico y el de las disciplinas que - cada una según sus métodos y su delimitación temática, mejor o peor acotadase empeñan en alcanzar resultados sin duda más rigurosos que aquellos a los que puede aspirar la filosofia; más rigurosos, sí, mejor apuntalados por la evidencia disponible, pero también, como es natural, menos ambiciosos.

Ambicioso, y penetrado por el prurito de aprender de los especialistas científicos de las diversas disciplinas relacionadas con el estudio de lo humano, lo es con creces este nuevo libro (El animal cultural: Biología y cultura en la realidad humana, Barcelona, Crítica, 1994).

Esta obra de Carlos París representa un intento de construcción personal de una antropología filosófica original y sistemática, sin por ello dejar de revelar a las claras su convicción de que el estudio filosófico de to humano es un asunto tan difícil, $\tan$ rodeado de escollos, tan resbaladizo incluso, que siempre será insuficiente cualquier acopio - por grande que sea - de resul- tados parciales de las ciencias (o cuasiciencias, habría que decir en algún caso) que, de cerca o de lejos, se interesan por temas relacionados con nuestra especie. De ahí que haya invertido un tiempo y un esfuerzo gigantescos en ponerse a la escucha de los cultivadores de esas disciplinas. Historia, antropología cultural, socio-biología, primatología, ecología, lingüística, diversas ramas de la sociología y mucho más: todo viene escudriñado, rastreado, consultado con inquieta avidez para hallar luces con las cuales proceder a generalizaciones no abusivas.

Mas no le va a la zaga la escucha atenta a lo que tengan que aportar los mismos filósofos, desde sus múltiples y encontrados enfoques. Hoy, cuando los filósofos nos encontramos generalmente divididos en campos - los analíticos no nos preocupamos por oír o leer a los «continentales»y, y viceversa-, Carlos París está atento a lo que se diga acerca del ser humano desde perspectivas tan variadas como las de Carlos Marx, Spengler, Ortega, Unamuno, Sartre, Heidegger, Wittgenstein, Austin, Popper, Chomsky, el materialismo eliminativista de Patricia Churchland...

Un filósofo analítico - como quien esto escribe- puede, sin embargo, no sentirse en su casa con este libro. La razón es que el autor ha tenido la capacidad de tomar de los debates y tratamientos de la filosofía analítica justamente sólo todo aquello que es (idigamos!) menos «típico» del filosofar analítico según se practica hoy. Tomemos un ejemplo: Carlos París discute el «Mundo III» de Popper (a esa discusión volveré 
mâs abajo); trátase, sin lugar a dudas, de un tema perfectamente respetable para un filósofo analítico; encontrará su lugar -mayor o menor, generalmente menoren las páginas de las revistas de filosofía analítica. Mas a menudo el debate sobre un tratamiento así $\longrightarrow$ que suele verse con mucha sospecha y que encuentra pocos defensores - se enmarca en una controversia mucho más amplia, en una serie de discusiones en torno a cuestioncs ontológicas, metafísicas, que involucran temas como el de la realidad o no de los meros posibles, y la distancia ontológica, o falta de clla, cntrc los tipos y las mucstras [digamos, entre «la palabra» «verde» -un elemento de lengua (en sentido saussureano) - y los millones de prolaciones de tal palabra que de hecho ocurren en el discurso oral o escrito -en el habla- (en sentido igualmente saussureano)]. Un analítico difícilmente debatiría acerca del Mundo III de Popper sin traer a colación a Gottlob Frege, David Lewis, Nicholas Rescher, o Alvin Plantinga. Nuestro autor, en cambio, prescinde de todo eso y sitúa claramente su tratamicnto alejado de las aguas turbias de la metafísica, $O$ eso intenta. Que lo consiga es otra cosa.

Asimismo, un debate con P. Churchland, en el campo analítico, sc ubicaría probablemente en el trasfondo de discusiones con y sobre Quine, las teorías de la superveniencia, los materialismos no eliminativistas, los reduccionismos de uno u otro matiz. Todo eso queda alejado de la perspectiva de Carlos París. Puede que, haya una razón importante: mientras que en esas controversias se discute - según puede parecer- un poco sen el aire», haciéndose antropología filosófica de butaca, autores como Patricia Churchland, por objetables que sean sus conclusiones, argumentan con mayor grado de cientificidad, de atención a los datos de las investigaciones empíricas. Este libro de Carlos París está, todo él, impregnado de esa pauta metodológica de no dar pasos en la reflexión filosófica sin tomar en consideración en cada momento lo que tengan que aportar los especialistas.

Comprendiendo ese escrúpulo, y hasta sintiendo para con ese tipo de actitud metodológica una vaga simpatía en principio, los analíticos persistirían en sostener que hay tremendas cuestiones -idigamos:- "conceptualcs» involucradas en arduos y espinosos problemas que, explicita o implicitamente, asoman aun en los argumentos de estudiosos que quicren ser «científicos*, y que esas cuestiones conceptuales han menester de un estudio que resulta ser aún más difícil, erizado de trampas, sin el cual será un tantico ilusorio creer que se ha avanzado en firme simplemente porque se ha filosofado prestando una atención enorme, atenta, erudita, a los aportes de los científicos y especialistas.

Desde luego Carlos París puede replicar a eso que - lo mismo que en tantas otras cosas- aqui tenemos un problema de proporción. Unos, en aras de ahondar en lo que - por razones de conveniencia y sin afân de precisión- podemos llamar «análisis conceptual», dedican tanto ticmpo y tanta energía a esa tarea que no les queda bastante para aprender de lo que puedan aportar las ciencias especializadas en el estudio riguroso de unas $\mathfrak{u}$ otras facelas de lo humano. Otros, entre los que se encuentra él, prefieren posiblemente dedicar sus máximos esfuerzos a ese aprendizaje.

IJuzgue el lector por sí mismo! Verosimilmente es éste uno de los problemas cn los que no toda la razón está de un solo lado. Y tambiến hay quizá en esto un problema de opción, de horizonte de intelección desde posiciones últimas de valor en torno a qué sea y para qué sirva la filosofia. A los amantes de un filosofar más adjetivo que sustantivo este libro habría de gustarles enormemente, pues deberían simpatizar con ese enfoque suyo básico. 
Carlos París, sin embargo, no aceptaría la caracterización de su filosofía como «adjetivista», porque, si bien el cree que la filosofia es una actividad de orden kene más uno» -estimando que no puede uno filosofar $\sin$ apoyarse en los datos y teorías de la ciencia, así como en otros aspectos de la cultura humana-, sostienc que eso no suprime la entidad propia del acto de elaboración filosófica, la apertura de preguntas que no se plantea la ciencia.

Justamente desde la perspectiva de un enfoque analítico «sustantivista»-p. ej., un holismo mitigado de orientación quineana- esa actitud metodológica aparecerá como adjetivista, toda vez que la misma establece una posterioridad de la filosofía respecto de los resultados de las ciencias particulares; aquélla presupondrá a éstas, mas no a la inversa. Y desde luego, y por encima de todo, la implementación del plan de trabajo de Carlos París - según se plasma en este libro- atribuye tal predominio, siquiera cuantitativo, al examen de los datos de las ciencias particulares que no mucho podría quedar para cuestiones más propiamente filosóficas, como éstas: qué sea una especie; si es un universal o un individuo disperso; cuáles son las condiciones necesarias y suficientes para que se individúe una especie; si se trataría o no de la misma especie humana -aun sin relación genética ni tal vez causal con nosotros-en el caso de que haya seres similares en otras galaxias o seres con muchas de nuestras características, mas no todas, en otros mundos posibles, etc; asimismo, cuándo «dos" micmbros de la especie son idénticos y cuándo, sin serlo, guardan alguna relación que prácticamente haga las veces de la identidad para lo que nos interesa [véase lo dicho en el párrafo $8 .^{\circ}$, comenzando por abajo, de la presente Nota en torno a la tesis de Derek Parfit en su libro Reasons and Persons]; o sea, un conjunto de cuestiones ontológicas que se debaten en la antropología filosófica de cuño analítico.
Sea como fuere, a todos los lectores -adjetivistas o no- habrá de resultarles este libro de un inmenso e inapreciable interés por su riqueza, su variedad de temas, y por su amplísima y documentada atención al detalle de los aportes especializados, tanto de los recientes cuanto de los menos recientes.

Sentadas esas consideraciones metodológicas, examinemos ahora someramente las tesis de fondo que defiende Carlos París en este libro. No hace falta perspicacia para percatarse de que lo que trata de brindarnos es una redefinición del hombre que rememora la clásica de animal racional, mas la corrige y puntualiza.

De un lado, Carlos París rechaza la visión tradicional de la definición, que considera plana y estática: la de entender una definición como una especie de conyunción o yuxtaposición de marcas o notas dadas de antemano, según el esquema del árbol de Porfirio. En lugar de eso, él ha propuesto un tratamiento dinámico en que los conceptos se reestructuran en el proceso de recuperación y recreación o reconstrucción en que elementos preexistentes en una estructuración anterior sc reestructuran de nuevas formas, siguiendo el proceso real de la evolución. (De nuevo un analítico objetará que al menos lo de Porfirio lo entiende claramente: decir que «hombre» se define como «animal racional» -o sea, que el predicado «es hombre» abrevia a «es animal y es racional»-... es algo que se puede formalizar. Dadas las condiciones de verdad de la conyunción en un sistema lógico que uno admita, pueden precisarse con rigor las condiciones necesarias y suficientes para llamar «hombre* a un ser, dada esa definición, u otra similar. Mas para nuestro presente tema, podemos dejar de lado esas consideraciones.

De otro lado - y esto es más relevante para nuestra actual discusión-, en lugar de tomar la racionalidad como lo definitorio, tómase aquí la culturalidad. La cul- 
tura, eso sí, tiene mucho que ver con la razón, evidentemente; pero ni todo lo racional es cultural ni viceversa. Lo más característico del ser humano es el enorme cúmulo de su actividad, de su vida, individual y en común, que posee los rasgos de lo cultural: $1 .{ }^{\circ}$ el ser algo adquirido y que no viene automáticamente dado con el patrimonio genético y que no se tendria sin esa adquisición; $20^{\circ}$ el que esa adquisición se acumule $\mathrm{y}$ se modifique en una tradición (lo cultural en esta faceta es lo que se transmite, lo que se pasa de unas generaciones a otras - nuevamente más allá de la transmisión genética-); $30^{\circ} \mathrm{el}$ ser algo que sólo se tiene en común, que reside en la colectividad, que únicamente tiene sentido y viabilidad por esa posesión conjunta, al paso que sería inadquirible e inutilizable en una situación de aislamiento o de extrema dispersión; $4 .^{\circ}$ la variabilidad, un rasgo que, más que una condición independiente, puede verse casi como un corolario de la adquiribilidad, aunque no se reduce del todo a ella: podría una especie scr capaz de adquirir unos hábitos de conducta que no se posean automáticamente por el patrimonio genético sin que tales hábitos fueran variables; $5 .^{\circ}$ la contingencia: no sólo no viene predeterminado por el mero hecho de tener un patrimonio genético el que se adquieran tales hábitos de comportamiento, sino que nada hay en general en la naturaleza de las cosas (ni en la del hombre ni en la de sus relaciones con otras especies) que permita predecir a ciencia cierta el surgimiento, desarrollo o mantenimiento de unos u otros patrones culturales. Resumiriamos todo eso diciendo que lo cultural es lo no-natural.

La racionalidad la sitúa Carlos París fundamentalmente en una de las tres grandes áreas en las que este libro estructura la evolución de la vida hacia la cultura: la de la información. Pero junto a ella se encuentra la técnica (véase más abajo), correspondiente a la «acción sobre el medio» y la visión del ser humano como «animal proyectivo», proporcionada al desarrollo de la reproducción morfológica y etiológica. Podría entonces decirse que Carlos París redefine al ser humano como homo faber $\mathrm{y}$, con mayor razón aún, que lo define como «animal proyectivo». (Su anterior libro, Filosofía, ciencia y sociedad, de hace más de veinte años, ya contenía un capitulo titulado precisamente: «Hacia una definición actual del hombre: un animal proyectivo».) La cultura y la definición del ser humano como animal cultural, por ende, resulta constituida por la integración de estas tres áreas y su interacción.

La contingencia a que he aludido un poco más atrás podría acaso matizarse (si bien no lo hace Carlos París, poco dado, al menos en este libro, a digresiones metafísicas, según lo he señalado ya). Tal vez esa contingencia sca sólo epistémica, una impredecibilidad desde nuestro humano y limitado punto de vista. $O$ tal vez sea sólo que ningún sector o territorio particular de los que estudian las diferentes disciplinas tiene una mirada lo suficientemente amplia como para poder formular las leyes de surgimiento y desarrollo de las culturas (y entonces la contingencia sería óntica sólo en esto: que ninguno de esos territorios de la realidad, por separado, está regido por unas leyes que predeterminen la evolución cultural -en resumen, algo similar a lo que era la contingencia para Leibniz-). $O$ puede tratarse de una contingencia ontica mas no absoluta. Carlos París no entra en tales disquisiciones. Saca uno la clara impresión de que no es nada favorable al determinismo histórico (una doctrina que ciertamente encuentra hoy pocos partidarios, si bien puede que sea eso cuestión de moda, at fin y al cabo).

El libro está muchísimo más destinado a explorar la culturalidad que la animalidad del ser humano. Veremos en seguida que -aunque no sin titubeos- se compromete implícitamente a la idea de que nuestra especie, más que un monopolio de la cultura, lo que tiene como peculiar es 
su grado de culturalidad, mucho más elevado que el de cualquier otra especie animal (si bien Carlos Paris se esfuerza por afirmar, en esa diferencia de suyo cuantitativa, lo que ve como un salto cualitativo; vide infra). En cambio, nada de esa índole viene sugerido con relación a la animalidad. De hecho es bastante rápido el análisis de la noción de animalidad. No desconoce nuestro autor cuán difícil es trazar esa frontera entre animales y no animales, no ya por lo aparentemente borroso de la misma, sino porque no está tan claro cuáles sean en general los rasgos pertinentes.

En cualquier caso, y ateniéndonos a una definición usual y tradicional de animal (como un ser viviente dotado de movilidad y de conocimiento, al menos perceptivo), cabría preguntarse si nuestra especie no lleva la animalidad más lejos que otras, si no la realiza en una medida mayor. Porque la movilidad, el despego de un suelo determinado, es seguramente efectuado por seres humanos en una medida que deja chica la que se plasme en los movimientos de cualquier otra especie. Ni parece menos claro que tambiên los humanos poseen en mayor medida que las demás especies del planeta el otro rasgo de la animalidad: el conocimiento - las plantas no perciben, ni conocen, aunque posean algún análogo de esas funciones-. Por otro lado, esa mayor animalidad - si es que se da-corre pareja con la mayor culturalidad; ésta puede verse como un medio por el cual se realiza la primera. De ser eso así, podríamos ver al ser humano como el animal animalísimo.

No es ésa la vía que sigue Carlos París, sin embargo. Para él, antes bien, aun en su consideración del hombre como animal, lo que hay que señalar no es que el ser humano lleve los rasgos definitorios de la animalidad a un grado más elevado que las demás especies (en este planeta), sino algo muy diferente: que este animal particular que es el hombre tiene, en su animalidad misma, rasgos cualitativos propios que lo separan del resto de los animales, rasgos biológicos que son los que fundan la culturalidad de nuestra especie: la estación vertical y la liberación corporal a ella unida; la capacidad autoprogramadora del cerebro y su maduración social en un dilatado proceso; así como, decisivamente, la prematureidad [característica singular del ser humano]. Lo que hace aquí Carlos París - y es el meollo de su construcciónes engarzar íntimamente ambos aspectos (culturalidad y animalidad), tratando de explicar la cultura desde sus raíces biológicas en dura crítica a lo que llama el «aislacionismo culturalista»,

Como anotación crítica a ese enfoque podría quien esto escribe sugerir una serie de experimentos mentales. Sin duda, dados los rasgos comunes de los vertebrados y en particular los mamíferos, la estación vertical ha supuesto ventajas $e$ inconvenientes, como las frecuentísimas desviaciones de columna que sufrimos; mas en otros mundos posibles (tal yez incluso en otras galaxias de este mismo mundo posible en que estamos) hay seres, tan inteligentes como nosotros por lo menos, con una estación no vertical (algunos de ellos son redondos o redondeados); seres con un número mayor de extremidades, desiguaIes entre si, que les permiten moverse mejor y manejar mejor varios instrumentos a la vez (iy mejores instrumentos!). Igualmente, entre las diversas alternativas que ensaya la naturaleza - cada una con su pro y su contra-, ésa de salir del útero materno con el grado particular de maduración que tiene el individuo de nuestra especie al alcanzar ese nuevo estadio - tras unos doscientos setenta días de vida - es una que ofrece perspectivas buenas desde varios puntos de vista, mas que puede que no sea optima; hombroides de otras galaxias o de otros mundos posibles salen del útero todavia antes, liberando así más pronto a sus madres de esa carga, y siendo amparados por la colectividad para su ulterior maduración; o tal vez se gestan 
en probetas, como una vuelta en espiral a la oviparidad (snegación de la negación»). (Por cierto, Carlos París en este libro evoca — de pasada- una hipótesis de ese tenor, como posibilidad futura, para nuestra especie, en la concepción feminista de Lidia Falcón. Aunque hoy por hoy es ciencia-ficción, no cabe duda de que ya la mera idea es apasionante y morcce toda la atención de los científicos; pasitos hacia eso ya se han dado, al fin y al cabo.)

Así pues, en el libro que estamos comentando de Carlos París el ser humano viene comprendido como una especie biológica en la cual se dan unas características que la singularizan -otros hominidos desaparecidos se aproximaron a ellas, pero no pudieron culminar su evolución-y que potencian de un modo único el recurso, como clave vital, a la cultura - recuperada y reconstruida desde manifestaciones anteriores-. Ábrese así una nueva fase de la evolución. Y una serie de responsabilidades en nuestra relación con la vida y el planeta.

Desde esa perspectiva, gran parte de su reflexión gira en torno a la dicotomía -0 falta de ella- entre natura y cultura. Dc ahí que la socio-biología ocupe, ya en el arranque de la tematización de Carlos París, un lugar destacadísimo que puede sorprender a otros, menos acostumbrados a ver en esa corriente o disciplina - -si lo es- un interlocutor de envergadura o de talla. Para muchos la socio-biología venía juzgada como una cspecie de moda pasajera o incluso algo peor que eso, una ideología interesadamente propagada por grupos empenados en encastillar determinados patrones vigentes de comportamiento $\mathrm{y}$ de relaciones sociales aureolándolos con el prestigio de lo innato, consustancial con la cspecie y, en suma, natural.

Carlos París presta, en cambio, muchísima y sosegada atención a esa corriente. De ser certera $-\mathrm{y}$, sobre todo, de serlo en sus primeras formulaciones, las más polềmicas, atrevidas y ambiciosas-, que- daría en entredicho un enfoquc de lo humano como el que quiere proponernos aquí Carlos París, ya que, en ese caso, las pautas principales de actuación y de relaciones entre los miembros de la especic vendrian marcadas por el patrimonio genético de manera punto menos que unívoca y constriñente.

Carlos Paris presta tan atenta y hasta casi complaciente consideración a la socio-biología que puede uno perder de vista que, si lo hace, es justamente porque la misma, de ser exitosa, constituiría el mayor desafio a sus tesis. Lo que sale a la luz de ese examen es, sin embargo, que, lejos de ser el corpus ideológico acartonado y casi iconoclástico que podría parecer a sus menos caritativos adversarios, la socio-biologia es una doctrina en evolución que se ha ido perfilando en un proceso de rectificación y autocrítica. Su programa inicial era estrecho de miras y desmedidamente reduccionista. Sus posiciones posteriores, matizadas, ofrecen esclarecimientos que no cabe desconocer. Porque al fin y al cabo la dicotomía entre naturaleza y cultura no ha de verse, a juicio de Carlos París, de manera radical, sino que la cultura también está en la naturaleza. Es natural en nuestra especie poseer ese alto grado de culturalidad, como lo es en otras tener sus respectivos grados de vida cultural - - de adquisición de hábitos no innatos, de variación no predeterminada genćticamente.

La impresión que yo saco, personalmente, de esa discusión es que, en la medida en que la socio-biología se revela razonable, lo hace aguando tantísimo su inicial programa, estirando y edulcorando tanto sus instrumentos y sus propuestas reducciones, que poco queda de distintivo $y$ caracteristico. Ciertamente que no es ése un destino peculiar de tal escuela. Situaciones muy parecidas afectan a menudo a muchos programas que, en su versión inicial, ejercian el enorme atractivo de lo novedoso, de las posiciones de rompe y 
rasga, mas que, al hacerse más sabias, más prudentes, iban quedando deslavazadas.

La socio-biología nos propuso - -en su versión más radical- una reducción de lo que parecía mera cultura a la naturaleza genéticamente predeterminada, llevando así a un extremo una desestimación de lo cultural como rasgo característico de lo humano. Las raíces de tal actitud no pucden ser superficiales, ya que - según lo recalca Carlos París- la noción misma de cultura es de aparición más bien tardía. Nuestro autor enfoca principalmente a Rousseau como un cuasi-introductor del concepto de cultura, aunque no precisamente en buena parte: para el ginebrino es lo natural en el hombre lo que es loable y deseable. Sin embargo, creo que en esa línea cabría ir mucho más lejos. La actitud de Rousseau tiene un claro precedente en Descartes, para quicn las fuentes del error son en gran medida los preceptores, mientras que un hombre aislado y que reflexionara en un desierto podría, por la razón natural, alcanzar la verdad. ( $Y$ desde luego uno se acuerda del filósofo autodidacta de Abentofail.) $Y$ frente a ese naturalismo cartesiano, Leibniz es un adalid de lo cultural, del acervo acumulativo de técnicas, prácticas y métodos, que no son alcanzables por el individuo aislado y que sólo se van alcanzando paulatinamente en una tradición cultural.

Pero muchísimo antes, ino tenemos en las discusiones de la Grecia clásica (principalmente en los debates iniciados por los sofistas -en torno a lo que es por naturaleza y lo que es por convención o estipulación-) una anticipación penetrante y hasta genial de una buena parte de la reflcxión contemporánea acerca de la cultura?

Para Carlos París ese concepto de la cultura, ganado en siglos recientes, ha de entenderse aquilatadamente. Si el joven Marx señalaba, con razón, que la cultura misma forma parte de la naturaleza, sólo en su madurez llega el autor del Capital a una visión mejor matizada. Parafraseando a Hegel diríamos que hay que ver la cultura no sólo (io no tanto?) en su comunión con la naturaleza o en su pertenencia indirecta a la misma, sino también en su oposición a la naturaleza. En su dimensión propiamente cultural el hombre ya no es un ser natural. Y eso sería lo que habría recalcado el Marx de los escritos maduros. Nuevamente tendriamos que -igual que lo cultural es to adquirido, conseguido a fuerza de trabajo y de ingenio- el concepto mismo de cultura habría que irlo ganando y adquiriendo, al paso que la vía de facilidad nos llevaría a desconocerlo o a retrotraerlo rápidamente a una faceta mâs de lo natural.

La cultura aparece así como un búho de Minerva, por lo vespertino de su vuelo - tanto en su plasmación dentro de la evolución de las especies cuanto en su conceptuación reflexiva en nuestro pensamiento-. Su dimensión más palmaria, más saliente, por más utilitaria, es la de la técnica (véase lo dicho más arriba sobre las tres áreas en las que Carlos París estructura la cultura). La cultura como técnica no es sino la cultura en general en su faceta instrumental, que es aquella por la que cobra una legitimidad desde el punto de vista de la naturaleza. Mas la técnica, evidentemente, se emancipa de esa sujeción inicial. Tal vez todo en la cultura sea en su comienzo técnica, articulación e invención de instrumentos, hábitos y complejos de relaciones que sirven a la preservación y al incremento del propio ser biológico de la especie; mas es obvio que el averiguar ecuaciones óptimas para resolver problemas de resistencia de materiales puede acabar siendo para muchos una razón de vivir en sí misma, sirva para lo que sirviere, o aunque no sirva para nada.

Por ese camino, conecta Carlos París la noción de técnica con otra de sus tres áreas culturales: la información. Si la técnica surge al principio utilitariamente, de suyo lo que encierra la noción misma de 
técnica son las posibilidades de hacer algo con vistas a un fin, y eso afecta a las relaciones mismas entre las cosas, tanto si nos interesa prácticamente llevarlo a cabo corno si no; lo que viene destilado así a fin de cuentas es el habérselas de unas cosas con respecto a otras, que es asunto de información.

De ahí que podamos entonces erigir la noción de información en lo único constitutivo de la cultura; es la tesis de Jesús Mosterín, que viene criticada por Carlos París. Para éste, lo equivocado en esa reducción es que espiritualiza la cultura: la información, en la visión de Mosterín, es algo inmaterial portado por las formas de las señales que la transmiten. Así vienen excluidas de la cultura las plasmaciones materiales, las catedrales, los puentes, las bibliotecas, los museos. Desde luego lleva razón Carlos París en que ese tratamiento suscitaría extrañeza y sorpresa en la mayoría de la gente. Sin embargo, una discusión más a fondo del asunto requerinía justamente un planteamiento ontológico, metafísico, del que se abstiene Carlos París.

Vino evocada más arriba la cuestión de las rclaciones entre tipos y muestras; una cuestión tratada ampliamente en filosofía del lenguaje y de la lógica a propósito de si los portadores de la verdad (y la falsedad) son proposiciones extralingüisticas, $\mathrm{u}$ oraciones tipo, $\mathrm{u}$ oraciones muestra, $\mathrm{y}$ en ese último caso, si son oraciones posibles o sólo oraciones efectivamente existentes en este mundo. Todo eso es lo que cstá también en tela de juicio en lo tocante a temas abordados por Carlos París, tanto en este punto de la discusión con Mosterín cuanto en otros lugares de su libro - p. ej., el debate en tomo al Mundo III de Popper.

Tomemos el ejemplo de este último, citado por Carlos París (p. 281): la sinfonía Júpiter, de Mozart. Para Mosterín lo cultural al respecto sería meramente la información vehiculada, que se plasma en partituras, discos, ejecuciones, cintas magnéticas o cualesquiera otras representacio- nes, sin reducirse a ellas. Para Popper justamente esa trascendencia con respecto a las vivencias subjetivas de la creación, de la audición y del recuerdo, a los actos físicos de ejecución, a su materialización significativa en el pentagrama y a la codificación en discos $\mathrm{u}$ otros portadores contingentes y perecederos es lo que hace que la sinfonía Júpiter sea una entidad «ideal», extra-material, un habitante del Mundo III; si bien ese Mundo III sólo cobra y conserva existencia en tanto en cuanto hay seres inteligentes con capacidades para inventar objetos asi, para apreciatlos $y$ hacer algo con ellos.

Es la dc Popper una tesis muy parecida a la concepción de la posibilidad que ha defendido Nicholas Rescher: la posibilidad de que haya una erupción volcánica estriba en su pensabilidad. (No, claro, en que sea efectivamente pensada.) A la objeción, que salta a la vista, de que ello encierra una circularidad, Rescher ha respondido con argumentos que no cabe recordar aquí (aunque no nos haya logrado convencer a los realistas metafísícos). Similarmente, Popper entiende que la existencia del Mundo III estriba también en la de seres como los humanos; es parasitaria respecto de ésta; mas, una vez que ha cobrado realidad propia, no es eliminable ni estrictamente reducible - salvo por desaparición de la colectividad de seres inteligentes.

Lo que un realista metafísico tendria ganas de decir es que un tipo - como la sinfonía Júpiter, El Quijote o cualquier otro- puede entenderse de diversas maneras, pero que todas ellas suponen una realidad que no comienza a existir con los seres inteligentes que lo piensan o plasman. Podemos, p. ej., ver a un tipo como una clase, infinitamente numerosa, de sus muestras o casos posibles; mas para evitar la circularidad, para ofrecer una dilucidación satisfactoria, hemos de admitir entonces la existencia de esas posibilidades, abrazando algún género de realismo modal. Alternativamente, podemos ver al 
tipo como un cúmulo (e. d. un conjunto) de muestras efectivamente existentes con tal de tener una concepción intensionalista y no extensionalista de los cúmulos. Otra alternativa es ver a los tipos como entidades no espacio-temporales (siguiendo pautas de Frege, o de Nicolai Hartmann, un filósofo poco aducido hoy en estas controversias, mas que tiene mucho que decirnos pertinente y valioso al respecto). Asi, para un filósofo analítico, en una controversia como ésta acerca de las entidades involucradas en la información y la vida cultural, sería menester debatir sobre realismos mucho más fuertes que ése de medio pelo de Karl Popper, que no es ni carne ni pescado.

Mas para Carlos París - a quien ya el Mundo III de Popper le resulta una hipostatización abusivamente ontologizadorapoca credibilidad tendrían -si es que se pusiera a discutirlas - no sólo concepciones como las de Frege, Nicolai Hartmann o Bertrand Russell (en los estadios iniciales de su filosofar), sino incluso como las de Quine (para quien los conjuntos existen perpetuamente independientemente de que haya hombres o no), Gustav Bergmann o David Lewis, varios de los cuales suelen venir considerados como materialistas.

Desde al menos uno de esos enfoques no será verdad que la información es extra-material o independiente de las plasmaciones materiales; a saber: desde la concepciốn de los tipos como cúmulos extensionales de muestras (casos) posibles, la identidad o mismidad de un cúmulo tal, siendo extensional, dependerá de a qué objetos abarque (y en qué medida lo haga) en cada mundo posible, con lo cual el producto cultural o informativo es lo que es no independientemente de cómo se transmita sino sólo en función, precisamente, de esa transmisión. (No de la particular transmisión en este mundo nuestro, claro.)

Carlos París, al rechazar la visión de Mosterín, descarta también - según lo acabo de apuntar- la proyección, por par- te de Popper, de lo que no es sino un «ámbito ecológico" hacia un mundo ideal, «bastante fantasmagórico», al que Popper dota de vida propia. Ambos rechazos abundan en la misma tesis básica de nuestro autor, que quiere que no se borre de lo cultural su materialidad, su enraizamiento natural, su entidad esencial y consustancial de productos del quehacer, de la labor, de un ser animal determinado, de un habitante del cosmos material y vital.

Insisto, sin embargo, en quc, si bien simpatizo profundamente con la motivación que lleva a Carlos París a esas posiciones, me parece muy dudoso que se consiga una altcrnativa convincente y filosóficamente creíble frente a las que critica nuestro autor sin acudir a ningún tratamiento especificamente metafísico de la naturaleza o índole de los tipos involucrados en la cultura - sean técnicos, artísticos, literarios, científicos, jurídicos o cualesquiera otros-. Carlos París piensa a este respecto que, si se entiende la metafísica como teoría de lo real, no solamente no la rehuye sino que es esencial en su construcción. Sin embargo, del elenco de problemas metafísicos cuya dilucidación se echa en falta en el libro estă ésa de si los objetos de la información y de la cultura tienen una existencia independientemente de que haya seres humanos, o si empiezan a existir cuando se los plasma o representa en obras producidas por nosotros, y cuáles son las condiciones de su identidad o individuación.

El penúltimo problema que voy a discutir en este comentario es el de la libertad. Para Carlos Paris, de entre los diferentes rasgos de lo cultural que hemos considerado más arriba el más significativo y el más característico de lo humano es el de la maleabilidad, la no sujeción a pautas prefijadas o predeterminadas en el patrimonio genético. La meditación en torno a ese rasgo de la cultura $y$, por consiguiente, del animal cultural la lleva a cabo trayendo a colación planteamientos de filó- 
sofos como Sartre, Ortega y Heidegger, que han insistido con énfasis particular en rasgos de lo humano estrechamente vinculados a ese de la plasticidad, maleabilidad o apertura.

Lo peculiar e innovador de la investigación de Carlos París respecto a la libertad y la plasticidad es que trata nuevamente de dar un fundamento biológico a tal visión. Dicho fundamento se encontraria en la peculiaridad de la reproducción humana, el nacimiento desvalido o prematuro y en los fenómenos de heterocronía, de juvenilización y larga maduración. No sorprenderá a nadie que en ese trasfondo Carlos París acentúe por encima de todo el valor de la libertad. Animal cultural que tiene motivos para enorgullecerse de no estar sujeto o constreñido a unas pautas genéticamente heredadas, es en la libertad - ausencia de sujeción, en el rebasar barreras o trabas del tipo que sean, en lo que estribará la plenificación de lo humano. (No pretende, empero, que la libertad humana se erija como una no sujeción absoluta del ser humano a pautas naturales.)

Es éste también el motivo más fuerte de desacuerdo entre Carlos París y quien esto escribe. No voy a cuestionar la maleabilidad, que es obvia (si bien a mi entender es sólo cuantítativamente superior en nuestra especie respecto a otras; véanse los últimos párrafos de esta Nota). Mas no se sigue de ahí que la malcabilidad misma sea lo más valioso (puede que lo más valioso sea algo que la maleabilidad hace posible o facilita); ni tampoco cabe saltar de maleabilidad a libertad, en algún sentido fuerte $y$ rico de la palabra «libertad».

$\mathrm{Y}$ ello por lo siguiente. Igual que con tantas otras nociones a las que se quiere revestir de particular importancia y significación, la de libertad, si se toma en un sentido fuerte y rico, abarca poco, al paso que, si se quiere hacer de ella un hilo de Ariadna, una clave axiológica central, seguramente scrá al precio de empobrecer y edulcorar la noción en exceso.

Por «libertad» podemos entender: o bien la ausencia de trabas o barreras (o la superación de las mismas), o bien, en concreto, la ausencia de barreras que estorben la realización de nuestros deseos. En el primer sentido basta con que algo lo reputemos bueno, deseable, valioso, para que veamos como barrera, estorbo u obstáculo cualquier cosa o situación que dificulte su realización, y, por tanto, para que veamos como libertad o liberación la eliminación de tal estorbo; independientemente de que el interesado desee o no ese algo valioso, o de que lo desee mâs o menos.

Así, un cristiano puede hablar de liberar a alguien del pecado, viéndolo como bueno aunque quien venga así liberado no lo desee. $Y$ muchos pueden hablar de las libertades positivas, de estar libre de hambre, enfermedad, desvalimiento, zozobra, inseguridad. Aunque a lo mejor una persona puede no desear que se la aleje del hambre (está haciendo huelga de hambre, p. ej.), o de la enfermedad (es un asceta, un Pedro Damián que disfruta flagelándose o llevando un cilicio que le va produciendo una dermatosis grave), o de la zozobra e inseguridad (es un Sigfrido que, renunciando a su invulnerabilidad, piensa que la vida es lucha, y es más bonita una lucha con mayor ricsgo).

Tal vez en esos casos lo único por lo que quepa legítimamente esforzarse sea porque esas personas tengan la opción de no pasar hambre, enfermedad, inseguridad, etc. Lo dudo. De hecho, si así fuera, no se explicarian las medidas vinculantes que rigen en nuestras sociedades y que imponen dosis nada desdeñables de protección paternalista. Y es que, desde luego, la infelicidad de un miembro de la sociedad afecta a otros; mas, sobre todo, nadie ha demostrado ese cacareado principio de libertad de que cada uno puede hacerse a sí mismo lo que le dé la real gana. No 
veo por quê, si es malo hacer mal o daño, deja de ser malo si la persona a quien se hace es el mismo hacedor. Aparte de que, si lleva razón Derek Parfit (en su libro Reasons and Persons, Oxford U. P., 1986) al sostener que la noción de identidad personal es de importancia y significación secundarias (un punto de vista al que fuertemente se inclina quien esto escribc), no parece que sea tan decisivo que la víctima de un atropello sea idéntica al atropellador.

De ser asî, la noción de libertad estará llamada a perder el protagonismo que se le quería asignar. $Y$ volveríamos a éticas como las de la antigüedad clásica, en las que desde luego no se rechazaba el valor subordinado e instrumental de la libertad (pues coeteris paribus uno tiene más goce cuanto más a sus anchas puede hacer que se cumplan sus deseos), pero que ponían cn un lugar más preeminente a valores como el placer, la virtud o el bienestar.

Si la frontera entre humanos y no humanos no fuese meramente de grado - que es el último punto de discusión, al que me voy a entregar en seguida -, si el ser humano fuera un cnte radicalnente novedoso y genuinamente único, que se apartara del destino común de los [otros] animales, cntonces tal vez se cntendería que lo más valioso para nuestra especie y sus miembros fuera esa libertad desgarrada y trágica, en cuyo duro altar habría que sacrificar, llegado el caso, vida, fruición, dicha, conocimiento, paz a amor. Si es meramente de grado nuestra diferencia respecto a nuestros parientes de otras especies - cercanos o lejanos--, entonces también parece que cn asunto de valores estamos como ellos, más o menos, y que prevalece por sobre los demás el valor de tener y alcanzar una buena vida.

He reservado para cl final de csta nota un problema que, sin embargo, es central en todo el tratamiento de Carlos París: el de las fronteras entre lo humano y lo no humano, entre el ámbito de los seres cul- turales y el de los carentes de cultura. Nuestro autor - tan asiduo en la consulta de los resultados de las investigaciones que atañen directa $o$ indirectamente a lo humano-- presta enorme atención a los sensacionales descubrimientos de la primatología reciente que han puesto de manifiesto la capacidad lingǘstica de nuestros cercanos parientes, los [otros] monos antropoicles: cómo han aprendido a comunicarse lingüísticamente (aunque no mediante lenguaje fonético, sino de signos como el de los sordomudos) varios miembros de especies estrechamente emparentadas con la nuestra; casos individuales, desde luego, mas a todas luces repetibles. Mientras que Chomsky y su escuela han impugnado esos resultados -que no abonan precisamente a favor de sus tesis neocartesianas-, muchos autores han visto en ellos fenómenos de inmenso valor y de gigantesca significación, tanto teórica cuanto asimismo práctica.

La actitud de Carlos París al respecto no queda del todo clara. De un lado, ve en esos descubrimientos una confirmación de que en la realidad hay continuidades y no hiatos; que cuanto viene a caracterizar a nuestra especie, como una de animales culturales, también se da en cierto modo - grado en otras especics. Por otro lado, sin embargo, Carlos París no parece dispuesto a llevar esa conclusión a sus últimas consecuencias, ni teóricas ni prácticas. No aborda el problema de si lo gradual de la diferencia entre humanos y no humanos ha de comportar por nuestra parte un tratamiento de nuestros parientes $\longrightarrow$ al menos de los cercanos, como los monos-que les reconozca derechos. Su consideración acerca del lenguaje animal se queda un poco a medio camino, truncada por el aserto de que la atención a esos descubrimientos ha de hacerse «sin llegar a borrar en modo alguno las fronteras entre el lenguaje humano y el zoológico».

Ahora bien, justamente lo que nos enseñan esas investigaciones es que sî se borran 
esas fronteras, $y$ se borran porque son borrosas. No es que desaparezcan. Es que es asunto de grado. No parece haber ni un solo rasgo (salvo uno deícticamente determinable por nexos de parentesco, mas no definible en términos de cualidades o propiedades universalmente repetibles) que caracterice a sólo todos los miembros de nuestra especie. Cualquier criterio estricto que queramos inventarnos dejará fuera a muchos a quienes el ordenamiento jurídico vigente considera seres humanos $y$, a fuer de tales, titulares de derechos. $Y$ cualquier criterio un poco más laxo o generoso dejará dentro a, por lo menos, algunos chimpancés, gorilas y orangutanes.

Igualmente, cualquier definición de la cultura corre riesgos paralclos de, o excluir a pautas que se dan, con mayor o menor variación, en grupos de la especie humana, o incluir a pautas de castores, aves y hasta - como lo reconoce Carlos París- insectos sociales. La conclusión que se le ofrece a nuestro autor, que parece que le asoma en varias ocasiones, como que la tuviera en la punta de la pluma, es que todas csas diferencias son de grado. Mas también reiteradas veces aflora una renuencia suya a abrazar ese enfoque gradualista. Una y otra vez, a la vista de resultados que empujan en esa dirección, los reconoce y aprecia, mas vuelve a su tesis de que nada de todo eso ha de llevar a una «confusa uniformidad zoológica» (p. 226), sino que hay un salto cualitativo en el paso de lo no humano a lo humano.

El lector ha podido percalarse de las divergencias que separan el tratamiento de Carlos París de los puntos de vista que propugnaría al respecto el autor de la presente nota crítica. Séame lícito terminar, no obstante, con una afirmación rotunda —no paliada por gradualizaciones-: la de que quienquiera que desee llevar a cabo una reflexión filosófica acerca de nuestra especie y su lugar en el entorno ecológico en que nos ha tocado nacer y vivir tiene muchísimo que ganar estudiando y meditando este libro de Carlos Paris Amador.

Agradezco cfusivamente a Luis Fernández Moreno, Manuel Liz y Carlos Paris sus criticas y observaciones a un borrador del presente artículo. Ni que decir tiene que los errures que han quedado son exciusivamente mios. 